\title{
Epithelial cell adhesion molecule (MOC31) antibody expression in salivary gland tumors and squamous cell carcinoma
}

\author{
Yaser Abdullah Aish Ahmed* \\ Jiamusi University Faculty of Dentistry, China
}

\begin{abstract}
Background: In past years, many studies have been carried out to understand the Epithelial cell adhesion molecule (MOC31) antibody in the immunohistochemical analysis of peritoneal mesothelioma and primary and secondary serous carcinoma of the peritoneum, in the differential diagnosis of adenocarcinoma and malignant mesothelioma in the metastatic papillary thyroid microcarcinoma. In these researches the medium used were the cells of liver, colon and thyroid gland. Our study is also about the Epithelial cell adhesion molecule (MOC31) antibody but in the cells of the salivary gland and oral cavity.
\end{abstract}

Objective: The aim of our study is to detect salivary gland tumors and oral squamous cell carcinoma by using epithelial cell adhesion molecule (MOC31) antibody, in the method called immunohistochemistry.

Method: 46 slides of Epithelial Dysplasia, oral squamous cell carcinoma (tongue), salivary gland tumor (polymorphic adenoma and Warthin tumor) and malignant tumor Acinic cell carcinoma, Adenocystic Carcinoma, Mucoepidermoid Carcinoma and Squamous Cell Carcinoma, , submandibular gland tumor, sublingual gland tumor, were studied under microscope using immunohistochemical, by using Streptavidin biotin Peroxidase Complex (SP IHC) staining method (SABC). The study consisted of 2 divided groups: Epithelial cell adhesion molecule (EpCAM) antibody, MOC31 (clone) group IHC-P 1:200 and KI67 antibody and CytoKeratin antibody (CK) group IHC-P 1:200.

Result: Warthin Tumor is the highly detectable tumor by MOC31 antibody having a 3+ positive degree and a percentage of positive tumor cells of $70-80 \%$, Adenocystic Carcinoma comes in the second position with a positive degree of $1+$ and a percentage of positive tumor cells of 5-10\%. In the third rank we have 3 tumors which are Oral Squamous Cell Carcinoma, Epithelial Dysplasia and Polymorphic Adenoma, all of them have $+/-$ positive degree. (Table 1), results of KI67 antibody, indicating that Acinic cell carcinoma, Oral Squamous Cell Carcinoma, Epithelial Dysplasia and Acinic cell carcinoma are in the first position after having a positive degree of 2+. Acinic cell carcinoma has a percentage of positive tumors cells of 21-30\%, Oral Squamous Cell Carcinoma has a percentage of $11-20 \%$, Epithelial Dysplasia has a percentage of 11-20\%, Adenocystic Carcinoma and Muco Epidermoid Carcinoma both come with a positive degree of 1+, Adenocystic Carcinoma has a percentage of positive tumors cells of 61-70\%, whereas Muco Epidermoid Carcinoma has a percentage of 5-10\%, Warthin Tumor comes last with a positive degree of $+/-$ (Table 2). The second group of results is as follows: the total number of slides for MOC 31 is 13 and for CytoKeratin antibody (CK) as well is 13, all of the slides were seen under microscope and the change in color of the tissue were seen. Brown color of the tissues was considered as change in color. Table 3 shows the results of MOC31 antibody and CytoKeratin antibody (CK) respectively. Table 3 shows that Warthin Tumor is the highly detectable tumor by MOC31 antibody having between $1+$ and 2+ positive degree and a percentage of positive tumor cells of 5-10\%, Adenocystic Carcinoma comes in the second position with a positive degree of +1 and a percentage of positive tumor cells of 5-10\% (Table 3). Table 4 shows the results of CytoKeratin antibody (CK), indicating that Warthin Tumor and Adenocystic Carcinoma. Warthin Tumor has mostly a positive degree of 2+ and a percentage of positive tumors cells between 50-60\% and 60-70\%. Adenocystic Carcinoma has a positive degree of 1+ and 2+, Adenocystic Carcinoma has a percentage of positive tumors cells of 50-60\% (Table 4).

Conclusion: First conclusion of our experiment would be that MOC31 antibody can detect salivary gland tumor which are Warthin Tumors, The second conclusion would be that MOC31 antibody cannot detect Acinic cell carcinoma, Oral Squamous Cell Carcinoma, MucoEpidermoid Carcinoma, Epithelial Displasia, Submandibular Gland Tumor, Polymorphic Adenoma, Sublingual Gland Tumors. The third conclusion of my research work is that MOC31 can be used in the detection of benign salivary gland tumors and it cannot be used in detecting malignant salivary gland tumors.

\section{Introduction}

Salivary glands are divided into major and minor salivary glands. Major salivary which are parotid, submandibular, and sublingual are paired structures. Minor glands exist in a sub mucosal location throughout the upper digestive tract starting from the nasal cavity and lips down to the esophagus and trachea. The risk for malignancy and the histopathological distribution of malignant tumors differs between major and minor salivary glands [1-8]. The incidence of malignancy in the parotid, submandibular, and minor salivary glands is $25 \%, 50 \%$, and $80 \%$, respectively. The hard palate is the most frequent site of origin of minor salivary gland tumors. The most common benign tumor of salivary gland origin is the pleomorphic adenoma. The parotid gland is the most common site of origin, followed by the submandibular gland and then by minor salivary glands [9-15].

Correspondence to: Yaser Abdullah Aish Ahmed, Jiamusi University Faculty of Dentistry, China, E-mail: dryaa2009@gmail.com

Keywords: epithelial cell adhesion molecule (EPCAM), MOC31(clone) antibody, KI67 antibody, cytokeratin antibody (CK), salivary gland tumors, oral cavity tumors, immunohistochemical streptavidin biotin peroxidase complex (SP IHC)

Received: May 10, 2015; Accepted: June 23, 2015; Published: June 27, 2015 
Squamous-cell carcinoma (SCC or SqCC) cancer of a squamous cell occurs as a form of cancer in diverse tissues, including the lips, floor of the mouth, tongue, esophagus, and others. Squamous cell carcinoma represents more than 90 percent of all head and neck cancers. The chief risk factors for oral squamous cell carcinoma are smoking and alcohol use. The combination of heavy smoking and alcohol abuse is estimated to raise the risk in women and in men exponentially. Squamous cell carcinoma of the tongue may also result from any chronic irritation, such as dental caries, overuse of chewing tobacco, or the use of betel quid. Oral lesions are asymptomatic initially, highlighting the need for oral screening. Most dental professionals carefully examine the oral cavity. The lesions may appear as areas of erythroplakia or leukoplakia and may be exophytic or ulcerated. Cancers are often indurated and firm with a rolled border. As the lesions increase in size, pain, dysarthria, and dysphagia may result. Any suspicious areas should be biopsied.

Epithelial cell adhesion molecule (EpCAM) antibody, MOC31 (clone): The official name of this EPCAM gene is "epithelial cell adhesion molecule." EPCAM is the gene's official symbol. The normal function of the EPCAM gene is as follows, the EPCAM gene provides instruction for making a protein known as epithelial cell adhesion molecule (EPCAM). This protein is found in epithelial cells which are the cells that line the surfaces and cavities of the body. The EpCAM protein is found spanning the membrane that surrounds epithelial cells, where it helps cells stick to one another (cell adhesion).

Immunohistochemistry or IHC refers to the process of detecting antigens (e.g., proteins) in cells of a tissue section by exploiting the principle of antibodies binding specifically to antigens in biological tissues. IHC takes its name from the roots "immuno," in reference to antibodies used in the procedure, and "histo," meaning tissue (compare to immunocytochemistry). The procedure was conceptualized and first implemented by Dr. Albert Coons in 1941.

\section{Materials and method}

\section{Materials}

1) 46 Tumor blockers, Epithelial Dysplasia, Oral squamous cell (Tongue, Palate and Floor of the mouth), Salivary gland tumor Benign(Polymorphic Adenoma and Warthin Tumor) and Malignant tumor(Adenocystic Carcinoma, Mucoepidermoid Carcinoma and Squamous Cell Carcinoma), Castman Diseases, Plasma Cytoma, Primary Amyloidosis and Chronic Sclerosing Sialadenitis.

2) H\&E stain or HE stain (Hematoxylin and Eosin stain)

3) Microscope

4) Glass Slides

5) MOC31 Antibody kit

6) KI67 Antibody kit

7) DAB Solution kit

\section{Method}

1) 1-Biopsy of tissue of salivary gland and oral cavity, taken post surgical intervention.

2) 2-Report of the surgeon taken for the selection of tissue. The report suggested the position of the tissue and the size of the tissue.
3) 3-The tissue selected from patients who were clinically diagnosed as salivary gland tumor and oral squamous cell carcinoma.

4) 4-Referring to the Hematoxylin and eosin stain (H\&E or HE stain), we detected tumor of the salivary gland and squamous cell carcinoma from the oral cavity.

5) 5-Under microscope, the H\&E stained tissue were observed and the abnormal change of tissue and nucleus, microphage and metastasis were being selected.

6) 6-Immunohistochemical, Streptavidin biotin Peroxidase Complex (SP IHC) staining method (SABC):

a) Making the sections (3-4um) of target tissue blockers.

b) Spreading out the sections and sticking the sections on the glass slides.

c) Scorching the section at $70^{\circ} \mathrm{C}$ for $4-5 \mathrm{hr}$.

d) Deparaffinization and rehydration with xylene and alcohol: xylene twice, Ethanol 100\%, 100\%, 90\%, 80\%, respectively.

e) Washing with PBS, $3 \mathrm{~min} \times 3$ times.

f) Pretreatment: boiling in citrate buffer (PH 6.0), with use of microwave for 10-15 min and making cool naturally to room temperature in citrate buffer.

g) Immersion with $3 \% \mathrm{H}_{2} \mathrm{O}_{2}$ methanol solution for $10 \mathrm{~min}$. (Maixin-Bio kit)

7) Washing with PBS, 3 min $\times 3$ times.

8) Blocking with normal working goat serum. (Maixin-Bio kit)

9) Applying the MOC31 (Maixin-Bio kit) (1:200 or 1:50) or Ki-67 (working solution) (Maixin-Bio regent) antibody overnight at $4^{\circ} \mathrm{C}$ temperature.

10) Washing with PBS, 3 min $\times 3$ times.

11) Applying the second antibody ( $\operatorname{IgG})$ for $45 \mathrm{~min}$. (Maixin-Bio kit)

12) Washing with PBS, 3 min $\times 3$ times.

13) Applying the Streptavidin-Peroxidase (SP) complex for 30min. (Maixin-Bio kit)

14) Washing with PBS, $3 \min \times 3$ times.

15) Visualizing with a chromogen: applying DAB working solution about 5-10 min and observing with microscope (Maixin-Bio kit).

16) Stopping visualization with flowing water for 5-10 min.

17) Counterstaining with methyl green for $20 \mathrm{~min}$.

18) Dehydration with Ethanol $80 \%, 90 \%, 100 \%, 100 \%$, and applying xylene twice, respectively.

19) Making dry with air-blower and covering slides immediately.

20) Observing positive sites and cells with microscope and classifying positive grades.

\section{Result}

First group of results are as follows; the total number of slides for MOC31 is 10 and for KI67 is 10 as well, all of the slides were seen under 
microscope and the change in color of the tissue were seen. Brown color of the tissues was considered as change in color. Table 1 below shows the results of MOC31 antibody and KI67 respectively.

Table 1 shows that Warthin Tumor is the highly detectable tumor by MOC31 antibody having a 3+ positive degree and a percentage of positive tumor cells of $70-80 \%$, Adenocystic Carcinoma comes in the second position with a positive degree of $1+$ and a percentage of positive tumor cells of $5-10 \%$, in the third rank we have 3 tumors which are Oral Squamous Cell Carcinoma, Epithelial Dysplasia and Polymorphic Adenoma, all of them have $+/$ - positive degree.

Table 2 below shows the results of KI67 antibody, indicating that Acinic cell carcinoma, Oral Squamous Cell Carcinoma, Epithelial Dysplasia and Acinic cell carcinoma are in the first position after having a positive degree of $2+$. Acinic cell carcinoma has a percentage of positive tumors cells of 21-30\%, Oral Squamous Cell Carcinoma has a percentage of 11-20\%, Epithelial Dysplasia has a percentage of 11$20 \%$, Acinic cell carcinoma has a percentage of $11-20 \%$, Adenocystic Carcinoma and MucoEpidermoid Carcinoma both come with a positive degree of $1+$, Adenocystic Carcinoma has a percentage of positive tumors cells of $61-70 \%$, whereas MucoEpidermoid Carcinoma has a percentage of 5-10\%, Warthin Tumor comes last with a positive degree of + /-.

Second group of results are as follows: The total number of slides for MOC31 is 13 and for CytoKeratin antibody (CK) is 13 as well, all of the slides were seen under microscope and the change in color of the tissue were seen. Brown color of the tissues was considered as change in color. Table 3 below shows the results of MOC31 antibody and CytoKreatin antibody respectively.

Table 3 shows that Warthin Tumor is the highly detectable tumor by MOC31 antibody having between $1+$ and $2+$ positive degree and a percentage of positive tumor cells of 5-10\%, Adenocystic Carcinoma

Table 1. Results of MOC31 antibody.

\begin{tabular}{|l|l|l|c|}
\hline No & Tumor Name & Positive Degree & $\begin{array}{c}\text { Percentage of Positive } \\
\text { Tumors cells }\end{array}$ \\
\hline 1 & Warthin Tumor & Positive (3+) & $70-80 \%$ \\
\hline 2 & Acinic cell carcinoma & Negative & - \\
\hline 3 & Oral Squamous Cell Carcinoma & Positive (+/-) & - \\
\hline 4 & Adenocystic Carcinoma & Positive (1+) & $5-10 \%$ \\
\hline 5 & Muco Epidermoid Carcinoma & Negative & - \\
\hline 6 & Epithelial Dysplasia & Positive (+/-) & - \\
\hline 7 & Submandibular Gland Tumor & Negative & - \\
\hline 8 & Acinic cell carcinoma & Negative & - \\
\hline 9 & Polymorphic Adenoma & Positive (+/-) & - \\
\hline 10 & Sublingual Gland Tumor & Negative & - \\
\hline
\end{tabular}

Table 2. Results of KI67 antibody.

\begin{tabular}{|l|l|l|c|}
\hline No & Tumor Name & Positive Degree & $\begin{array}{c}\text { Percentage of } \\
\text { Positive Tumors cells }\end{array}$ \\
\hline 1 & Warthin Tumor & Positive (+/-) & - \\
\hline 2 & Acinic cell carcinoma & Positive (2+) & $21-30 \%$ \\
\hline 3 & Oral Squamous Cell Carcinoma & Positive (2+) & $11-20 \%$ \\
\hline 4 & Adenocystic Carcinoma & Positive (1+) & $61-70 \%$ \\
\hline 5 & Muco Epidermoid Carcinoma & Positive (1+) & $5-10 \%$ \\
\hline 6 & Epithelial Dysplasia & Positive (2+) & $11-20 \%$ \\
\hline 7 & Submandibular Gland Tumor & Negative & - \\
\hline 8 & Acinic cell carcinoma & Positive $(2+)$ & $11-20 \%$ \\
\hline 9 & Polymorphic Adenoma & Negative & - \\
\hline 10 & Sublingual Gland Tumor & Negative & - \\
\hline
\end{tabular}

Table 3. Results of MOC 31 antibody, with Warthin Tumor and Adenocystic Carcinoma.

\begin{tabular}{|l|l|l|c|}
\hline No & Tumor Name & Positive Degree & $\begin{array}{c}\text { Percentage of Positive } \\
\text { Tumors cells }\end{array}$ \\
\hline 1 & Warthin Tumor & Positive (1+) & $70-80 \%$ \\
\hline 2 & Warthin Tumor & Positive (2+) & $50-60 \%$ \\
\hline 3 & Warthin Tumor & Positive (2+) & $70-80 \%$ \\
\hline 4 & Warthin Tumor & Positive (2+) & $50-60 \%$ \\
\hline 5 & Warthin Tumor & Positive (1+) & $50-60 \%$ \\
\hline 6 & Warthin Tumor & Positive (2+) & $50-60 \%$ \\
\hline 7 & Warthin Tumor & Positive (1+) & $30-40 \%$ \\
\hline 8 & Warthin Tumor & Positive (2+) & $70-80 \%$ \\
\hline 9 & Warthin Tumor & Positive (2+) & $70-80 \%$ \\
\hline 10 & Warthin Tumor & Positive (2+) & $50-60 \%$ \\
\hline 11 & Warthin Tumor & Positive (1+) & $30-40 \%$ \\
\hline 12 & Adenocystic Carcinoma & Positive (+/-) & - \\
\hline 13 & Adenocystic Carcinoma & Positive (1+) & $5-10 \%$ \\
\hline
\end{tabular}

Table 4. Results of CytoKeratin antibody (CK), with Warthin Tumor and Adenocystic Carcinoma.

\begin{tabular}{|l|l|l|c|}
\hline No & Tumor Name & Positive Degree & $\begin{array}{c}\text { Percentage of Positive } \\
\text { Tumors cells }\end{array}$ \\
\hline 1 & Warthin Tumor & Positive (2+) & $70-80 \%$ \\
\hline 2 & Warthin Tumor & Positive (2+) & $50-60 \%$ \\
\hline 3 & Warthin Tumor & Positive (2+) & $70-80 \%$ \\
\hline 4 & Warthin Tumor & Positive (2+) & $50-60 \%$ \\
\hline 5 & Warthin Tumor & Positive (2+) & $50-60 \%$ \\
\hline 6 & Warthin Tumor & Positive (2+) & $50-60 \%$ \\
\hline 7 & Warthin Tumor & Positive (2+) & $50-60 \%$ \\
\hline 8 & Warthin Tumor & Positive (2+) & $70-80 \%$ \\
\hline 9 & Warthin Tumor & Positive (2+) & $70-80 \%$ \\
\hline 10 & Warthin Tumor & Positive (2+) & $50-60 \%$ \\
\hline 11 & Warthin Tumor & Positive (2+) & $70-80 \%$ \\
\hline 12 & Adenocystic Carcinoma & Positive (2+) & $50-60 \%$ \\
\hline 13 & Adenocystic Carcinoma & Positive (1+) & $50-60 \%$ \\
\hline
\end{tabular}

comes in the second position with a positive degree of $1+$ and $+/-$ and a percentage positive tumor cells of $5-10 \%$.

Table 4 below shows the results of CytoKeratin antibody (CK), indicating that Warthin Tumor and Adenocystic Carcinoma. Warthin Tumor has mostly a positive degree of $2+$ and a percentage of positive tumors cells between $50-60 \%$ and $60-70 \%$. Adenocystic Carcinoma and come with a positive degree of $1+$ and $2+$, Adenocystic Carcinoma has a percentage of positive tumors cells of $50-60 \%$.

\section{Discussion}

During experiment we studied 46 slides of tissues obtained after surgical interventions of patients suspected to have salivary gland tumor and oral squamous carcinoma. The aim of our study was to detect salivary gland tumor and oral squamous cell carcinoma by using epithelial cell adhesion molecule (MOC31) antibody, in the method called immunohistochemistry. Method: In the first group 20 slides of Epithelial Dysplasia, oral squamous cell carcinoma (tongue), salivary gland tumor polymorphic adenoma and Warthin tumor and malignant tumor Acinic cell carcinoma, Adenocystic Carcinoma, Mucoepidermoid Carcinoma and Squamous Cell Carcinoma, submandibular gland tumor, sublingual gland tumor, were studied under microscope using immunohistochemical, by using Streptavidin biotin Peroxidase Complex (SP IHC) staining method (SABC).

The study consisted of 2 divided groups: Epithelial cell adhesion molecule (MOC31) antibody, MOC31 (clone) group IHC-P 1:200 and 


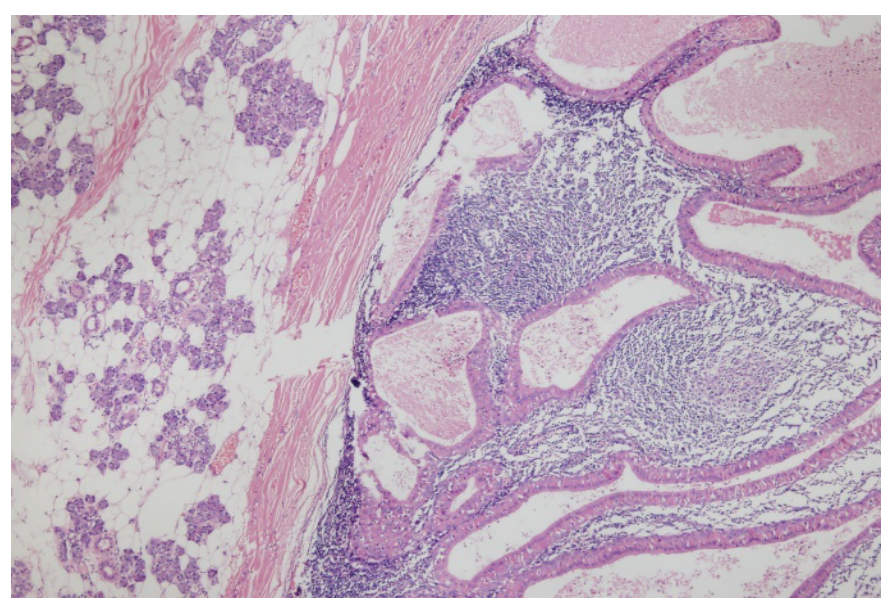

Figure 1. Warthin Tumor HE stain (4X).

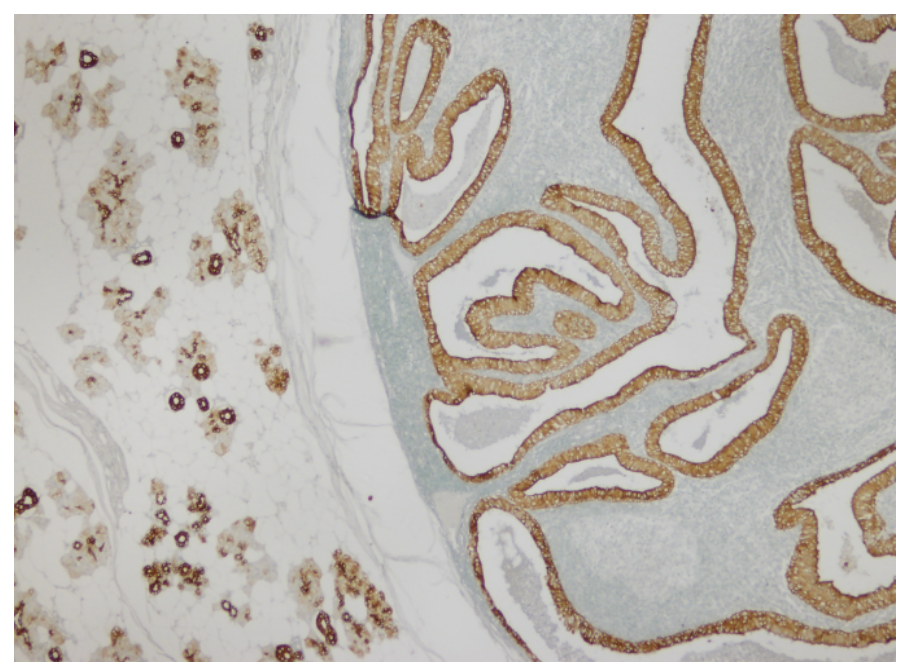

Figure 2. Warthin Tumor MOC31 antibody (4X).

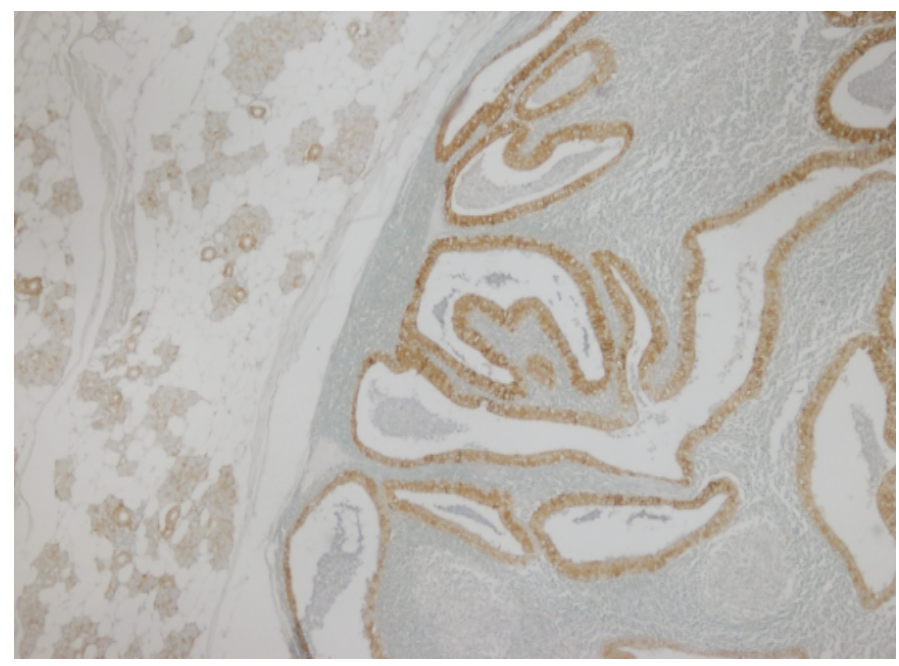

Figure 3. Warthin Tumor CK antibody (4X).

KI67 antibody group IHC-P 1:200. Our first group of results were as follows; the total number of slides for MOC31 was 10 and our control group which was a group of KI67 antibody slides as well had 10, all of the slides were seen under microscope and the change in color of the tissue were seen. Our first groups of results are as follows; the total number of slides for MOC31 was 10 and for KI67 as well is 10, all of the slides were seen under microscope and the change incolor of the tissue were seen. Brown color of the tissues was considered as change in color.

Table 1 shows the results of MOC 31 antibody and KI67 respectively. Table 1 shows that Warthin Tumor is the highly detectable tumor by MOC31 antibody having a $3+$ positive degree and a percentage of positive tumor cells of $70-80 \%$, Adenocystic Carcinoma comes in the second position with a positive degree of $1+$ and a percentage $f$ positive tumor cells of $5-10 \%$, in the third rank we have 3 tumors which are Oral Squamous Cell Carcinoma, Epithelial Dysplasia and Polymorphic Adenoma, all of them have $+/$ - positive degree.

Table 2 shows the results of KI67 antibody, indicating that Acinic cell carcinoma, Oral Squamous Cell Carcinoma, Epithelial Dysplasia and Acinic cell carcinoma are in the first position after having a positive degree of $2+$. Acinic cell carcinoma has a percentage of positive tumors cells of 21-30\%, Oral Squamous Cell Carcinoma has a percentage of $11-20 \%$, Epithelial Dysplasia has a percentage of $11-20 \%$, Acinic cell carcinoma has a percentage of $11-20 \%$, Adenocystic Carcinoma and Mucoepidermoid Carcinoma both come with a positive degree of $1+$, Adenocystic Carcinoma has a percentage of positive tumors cells of 61-

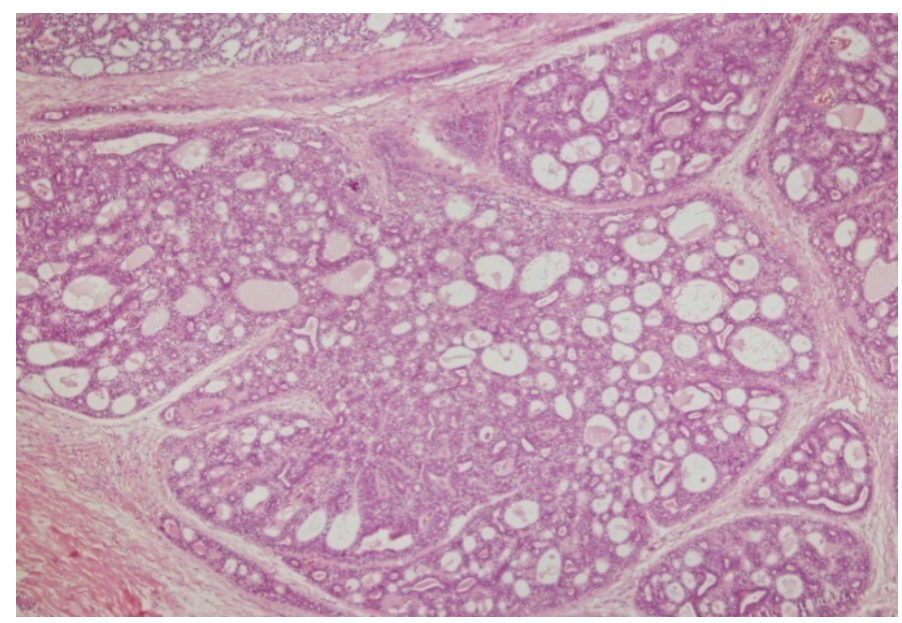

Figure 4. Adenocystic Carcinoma HE stain (10X).

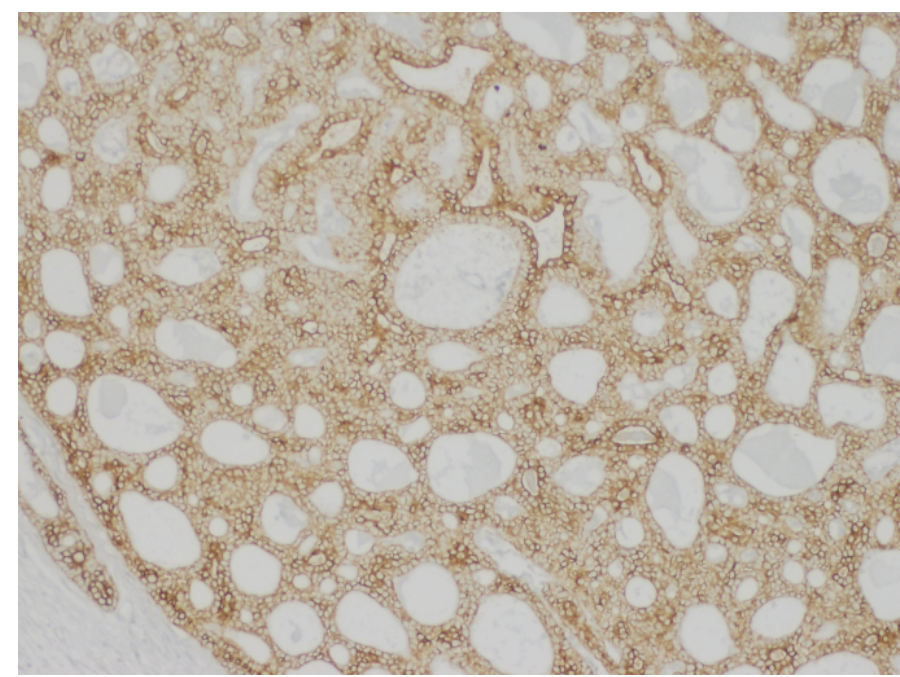

Figure 5. Adenocystic Carcinoma MOC31 antibody (10X). 


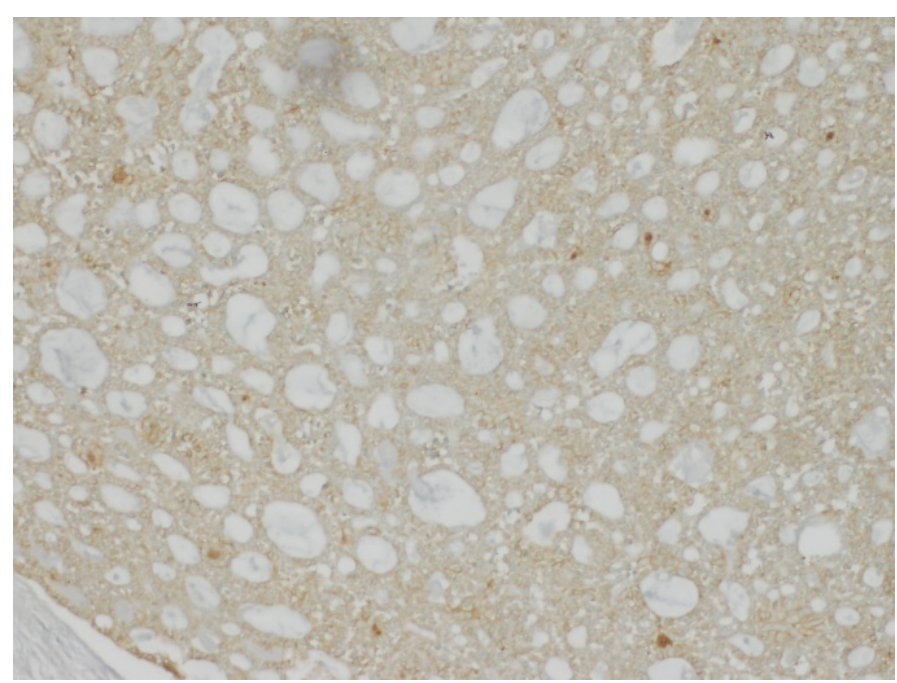

Figure 6. Adenocystic Carcinoma CK antibody (4X).

70\%, whereas Mucoepidermoid Carcinoma has a percentage of 5-10\%, Warthin's Tumor comes last with a positive degree of $+/$-. In the second group 26 slides of Warthin's tumors and Adenocystic Carcinoma with MOC31 and CytoKeratin antibody (CK) were being used, which had the following results: the total number of slides for MOC31 was 13 and for CytoKeratin antibody (CK) as well was 13, all of the slides were seen under microscope and the change in color of the tissue were seen. Brown color of the tissues was considered as change in color.

Table 3 shows the results of MOC31 antibody and CytoKeratin antibody respectively. Table 3 shows that Warthin Tumor is the highly detectable tumor by MOC31 antibody having between $1+$ and $2+$ positive degree and a percentage of positive tumor cells of $5-10 \%$, Adenocystic Carcinoma comes in the second position with a positive degree of $1+$ and $+/$ - and a percentage positive tumor cells of $5-10 \%$. The results of CytoKeratin antibody (CK), indicating that Warthin Tumor and Adenocystic Carcinoma. Warthin Tumor has mostly a positive degree of $2+$ and a percentage of positive tumors cells between $50-60 \%$ and $60-70 \%$. Adenocystic Carcinoma and come with a positive degree of +1 and +2 , Adenocystic Carcinoma has a percentage of positive tumors cells of $50-60 \%$.

\section{Conclusion}

1. First conclusion of our experiment would be that MOC31 antibody can detect salivary gland tumor which are Warthin Tumors.
2. The second conclusion would be that MOC31 antibody cannot detect Acinic cell carcinoma, Oral Squamous Cell Carcinoma, Mucoepidermoid Carcinoma, Epithelial Dysplasia, Submandibular Gland Tumor, Polymorphic Adenoma, Sublingual Gland Tumor.

The third conclusion of my research work is that MOC31 can be used in the detection of benign salivary gland tumors and it cannot be used in detecting malignant salivary gland tumors.

\section{References}

1. Jatin S (2010) Common tumor of salivary gland. H N Sur NC J 41: 234-239.

2. Ramos Vara JA (2005) Technical Aspects of Immunohistochemistry. Vet Pathol 42: 405-426. [Crossref]

3. Su XY, Li GD, Liu WP, Xie B, Jiang YH (2011) Cytological differential diagnosis among adenocarcinoma, epithelial mesothelioma, and reactive mesothelial cells in serous effusions by immunocytochemistry. Diagn Cytopathol 39: 900-908. [Crossref]

4. Kundu UR, Krishnamurthy S (2011) Use of the monoclonal antibody MOC-31 as an immunomarker for detecting metastatic adenocarcinoma in effusion cytology. Cancer Cytopathol 119: 272-278. [Crossref]

5. Sciavolino PJ, Wing J, Augustus M (2008) The effect of using MOC31 in diagnostic field. J EURO 8: 345-349.

6. Yoshiura KI, Murray JC (2010) Sequence and chromosomal assignment of human BAPX, Hecksher-Sørensen J 7: 21-29.

7. Tucker AS, Watson RP, Lettice LA (2004) Detection of cancer in the field of oral pathology. J O PATH. 6: 45-47.

8. Ordóñez NG (2012) Mesotheliomas with small cell features: report of eight cases. Mod Pathol 25: 689-698. [Crossref]

9. Ordóñez NG (2012) Pleomorphic mesothelioma: report of 10 cases. Mod Pathol 25: 1011-1022. [Crossref]

10. Inoue H, Rudnick A, German MS (2009) Metastatic cancer and the pathology. EURO $J 4: 34-41$.

11. Li D, Wang B, Hu Q, Shen Y, Xu D, et al. (2014) Diagnostic accuracy of MOC-31 for malignant effusions: a meta-analysis. Tumour Biol 35: 6003-6009. [Crossref]

12. Sterlacci W, Savic S, Fiegl M, Obermann E, Tzankov A (2014) Putative stem cell markers in non-small-cell lung cancer: a clinicopathologic characterization. $J$ Thorac Oncol 9: 41-49. [Crossref]

13. Fong D, Seeber A, Terracciano L, Kasal A, Mazzoleni G, et al. (2014) Expression of EpCAM(MF) and EpCAM(MT) variants in human carcinomas. J Clin Pathol 67: 408-414. [Crossref]

14. Morgan RL, De Young BR, McGaughy VR, Niemann TH (1999) MOC-31 aids in the differentiation between adenocarcinoma and reactive mesothelial cells. Cancer 87 : 390-394. [Crossref]

15. King JE, Thatcher N, Pickering CA, Hasleton PS (2006) Sensitivity and specificity of immunohistochemical markers used in the diagnosis of epithelioid mesothelioma: a detailed systematic analysis using published data. Histopathology 48: 223-232. [Crossref]

Copyright: (C2015 Ahmed YAA. This is an open-access article distributed under the terms of the Creative Commons Attribution License, which permits unrestricted use, distribution, and reproduction in any medium, provided the original author and source are credited. 